\title{
Microstructure of a High Strength AZ91 Alloy Processed by Severe Plastic Deformation
}

\author{
Qiong $\mathrm{Xu}^{1,2}$, Aibin $\mathrm{Ma}^{2,3}$ and Yuhua $\mathrm{Li}^{2,3}$, Chaoying $\mathrm{Ni}^{1}$ \\ 1. Department of Materials Science \& Engineering, University of Delaware, DE, USA \\ 2. College of Mechanics and Materials, Hohai University, Nanjing, China. \\ 3. Suqian Institute of Hohai University, Suqian, China
}

Magnesium alloys can significantly reduce fuel consumption for their low density, high strength and good formability [1]. AZ91 alloy is the most widely used magnesium alloy and numerous work has been done to improve the macro-properties, especially mechanical behaviors by severe plastic deformation (SPD). However, more work remains to be done to explore the deformation mechanism that leads to grain and phase changes in AZ91 alloy $[2,3]$.

In this study, we prepared a grain-refined and high strength AZ91 magnesium alloy from commercial ascast product by SPD consisting of high passes of equal channel angular pressing (ECAP) and hot rolling (HR). The as-cast alloy contains $9.01 \mathrm{wt} \%$ Al, $0.71 \mathrm{wt} \% \mathrm{Zn}$, and $0.18 \mathrm{wt} \% \% \mathrm{Mn}$. Samples with a dimension of $40 \mathrm{~mm} \times 40 \mathrm{~mm} \times 100 \mathrm{~mm}$ were processed through an ECAP die at $250^{\circ} \mathrm{C}$ for 16 passes. Pieces of the specimen with a dimension of $40 \mathrm{~mm}$ x $100 \mathrm{~mm}$ x $4 \mathrm{~mm}$ were cut from inside the ECAP-ed sample and rolled to a thickness of $1 \mathrm{~mm}$ at $300{ }^{\circ} \mathrm{C}$ with a press of $10 \%$. The microstructure and morphology were examined by optical microscopy (OM) and a Zeiss Auriga 60 focused ion beam/field emission scanning electron microscope (FIB/SEM). TEM analysis was made with a JEOL JEM-2010 field emissions transmission electron microscope at an accelerating voltage of $200 \mathrm{kV}$.

Characterization shows remarkable improvements in the microstructure and strength of the material after SPD. An average strength value of $489 \mathrm{MPa}$ was achieved using tensile test. Fig.1 (a) shows the microstructure of as-cast material, indicating a typical dendritic structure of primary $\alpha-\mathrm{Mg}$ with an average size of $150 \mu \mathrm{m}$ separated by a network of $\gamma-\mathrm{Mg}_{17} \mathrm{Al}_{12}$ precipitates. Fig. 1 (b) and (c) exhibit the effect of ECAP and SPD (ECAP+HR) on the microstructure in which in addition to a significant difference of the overall structural textures from the as-cast structures, the secondary phase grains of $\gamma$ $\mathrm{Mg}_{17} \mathrm{Al}_{12}$ which has great hardness are broken to smaller pieces and thin strips distributed in the matrix grains which are severely deformed after ECAP as shown in Fig.1 (b). Fig.1 (c) shows a lower proportion of $\gamma-\mathrm{Mg}_{17} \mathrm{Al}_{12}$, indicating solid solution happened during the further rolling after ECAP.

Fig. 2 exhibits the SEM images and corresponding EDS maps of SPD-ed AZ91 alloys cut across an area of secondary phase. After the SPD, these precipitates appear broken apart and are mechanically mixed with local matrix and dispersed uniformly within a small area. Fig. 3 shows the TEM microstructure of the SPD-ed sample in which small grains with sizes of $50 \mathrm{~nm} \sim 200 \mathrm{~nm}$ are generated due to recrystallization. $\mathrm{Mg}_{17} \mathrm{Al}_{12}$ phases precipitate along grain boundaries during SPD and hinder the growth of recrystallization grains. Large numbers of dislocations are generated around the precipitate grains (Fig.3 (b)). Nano-bands and twin bands can also be observed (Fig.3 (c)). There are also angular Al-Mn phases remaining in the structure (Fig.3 (d)). These characteristic structures can effectively influence the mechanical property of the material.

In summary, SPD dramatically changes the microstructure of the material and refines the grain to 
nanoscale, accompanied by recrystallization and second phase precipitation. The severe deformation also causes the generation of high density of dislocations and nano-bands. The grain refinement, the formation of secondary phase $\mathrm{Mg}_{17} \mathrm{Al}_{12}$ and the significant density of crystal defects may explain observed high strength $(489 \mathrm{MPa})$ of the processed alloy compared to a low value $(214 \mathrm{MPa})$ of its ascast counterpart [4].

\section{References:}

[1] K. B. Nie et al, Materials Science and Engineering: A 624(29) (2015), p. 157.

[2] G. Faraji et al, Journal of Materials Science \& Technology 30(2) (2014), p.134.

[3] G. Faraji, P. Asadi, Materials Science and Engineering: A, 528(6) (2011), p. 2431.

[4] The authors acknowledge funding from the Fundamental Research Funds for the Central Universities (Grant No. HHU2016B45314). Dr. Ni and Dr. Ma are thanked for their many useful discussions and contributions to this work.
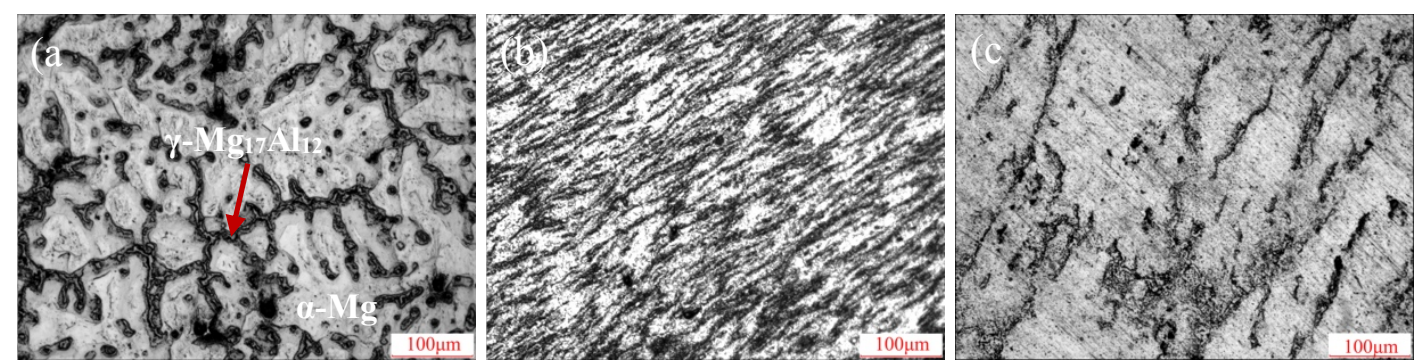

Figure 1. OM photograph of AZ91 alloy: (a) as-cast; (b) ECAP-ed; (c) SPD-ed.
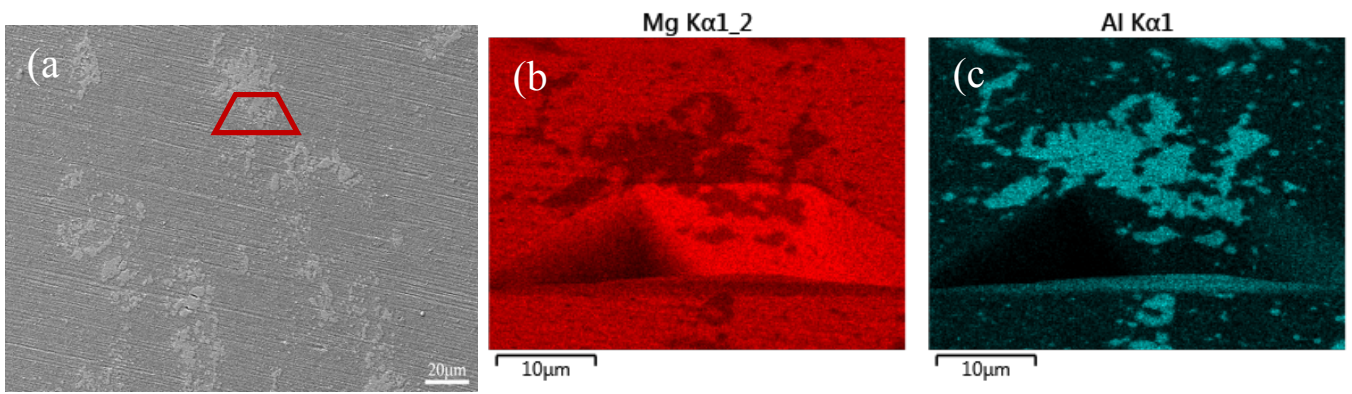

Figure 2. SEM and EDS photograph of SPD-ed AZ91 alloy.
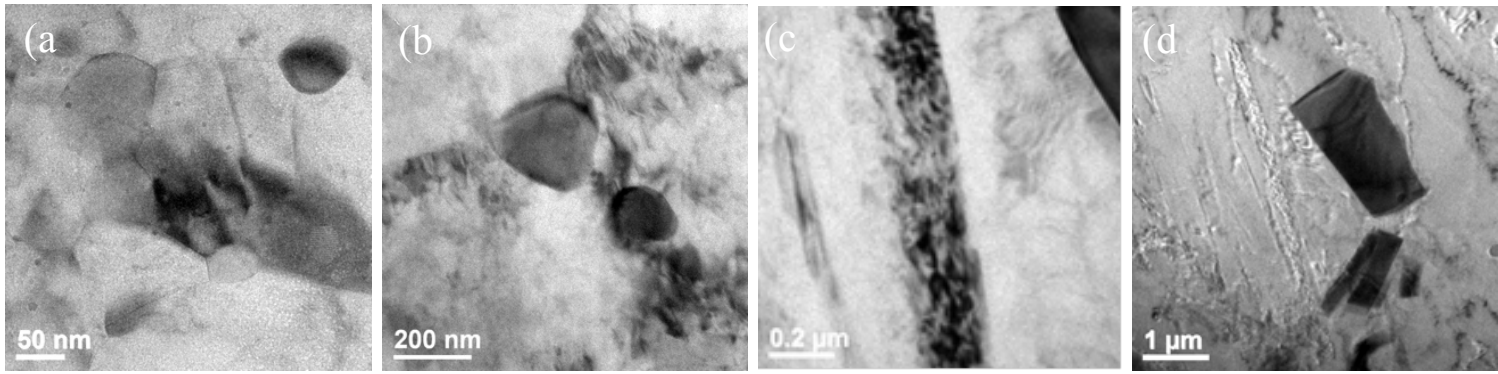

Figure 3. TEM photograph of SPD-ed AZ91 alloy. 